\title{
Contribuições das ciências cognitivas para o estudo da construção do conceito de justiça
}

\author{
Contributions of cognitive sciences to the construct of the concept of justice
}

${ }^{[a]}$ Mestre em Psicologia pela Universidade Federal do Paraná, doutoranda em Direito pela Pontifícia Universidade Católica do Paraná (PUCPR), professora do curso de Psicologia da mesma instituição, Pinhais, PR Brasil, e-mail: cristina.n@pucpr.br

${ }^{[b]}$ Doutor em Filosofia pela Universidade Federal de São Carlos (UFSCar), professor do Programa de Pós-Graduação em Filosofia da Pontifícia Universidade Católica do Paraná (PUCPR), Curitiba, PR - Brasil, e-mail: kleber.c@pucpr.br

Recebido: 29/04/2013 Received: 04/29/2013

Aprovado: 29/05/2013 Approved: 05/29/2013
Maria Cristina Neiva de Carvalho[a], Kleber Bez Birolo Candiotto ${ }^{[b]}$

\begin{abstract}
Resumo
O presente trabalho objetiva apresentar inicialmente a questão-problema referente ao aumento da judicialização da vida social, que contrasta com um sistema jurídico com sinais importantes de ineficácia e ineficiência. As causas repetitivas se caracterizam como uma das variáveis colaboradoras para esse quadro. Especificamente nas demandas dos serviços jurídicos relacionados aos conflitos entre pessoas que mantêm relação pessoal e/ou social, observa-se que, embora o sistema de justiça seja procurado, o que ele pode ofertar não vai ao encontro do que o jurisdicionado espera. Evidencia-se, existir uma concepção pessoal de justiça diversa do que a prestação jurisdicional pode oferecer. Assim, o estudo do desenvolvimento da formação de conceitos parece ser uma via para compreensão de como se dá o processo de conhecer, mais especificamente, como se "conhece" o que é justiça. Recorre-se a alguns pressupostos das ciências cognitivas, em especial às vertentes que se utilizam do conceito de enação para explicação do conhecimento humano. Conclui-se que a percepção que o sujeito tem de justiça é resultante da articulação de uma rede de estruturas, na qual se inclui o substrato biológico que, a partir das relações como o meio social, constrói representações dos fatos da realidade. Essa relação se estabelece de maneira circular, segundo a análise de Francisco Varela, e retrata a visão do paradigma da complexidade defendido por Edgar Morin, o que pode ser um subsídio para as ciências jurídicas e para sujeitos que buscam o sistema de justiça encontrarem novas estratégias para enfrentamento da judicialização da vida.
\end{abstract}

Palavras-chave: Ciências cognitivas. Conceito de justiça. Enação. Formação de conceitos.

\section{Abstract}

The following study aims to present the problem question related to the increase of the judicialization in social life, which contrasts to a legal system with signs of inefficiency and ineffectiveness. The constant causes are characterized as one of the variables that collaborate to this scenario. In the demands of legal services associated to conflicts between people that maintain personal and/ or social relationship, it is observed that even when the legal system is sought, not always it can provide what is expected by the demandant. It is evident the existence of a personal conception of justice, which differs from what the jurisdictional service is able to offer. Thus, the study of the

Psicol. Argum. 2013 jul./set., 31 (73), 529-536 
development of concept formation seems to be a way to investigate the mechanisms involved in the process of knowing, more specifically, the manner in which people understand "justice". Reference is also made to some presuppositions of cognitive science, especially those aspects that use the concept of enaction to explain human knowledge. It concludes that the subject's perception about justice is a result of combining network structures, which includes the biological substract that, in association with the social environment, builds representations of facts of reality. According to the analysis of Francisco Varela, this relation is established in a circular manner and portrays the vision of the complexity paradigm defended by Edgar Morin, which can be a subsidy for legal sciences and subjects who seek justice system, finding new strategies to deal with the legalization of life.

Keywords: Cognitive sciences. Concept of justice. Enaction. Concept formation.

\section{Introdução}

Tem se mostrado um grande desafio para o sistema de justiça brasileiro conquistar a eficiência e eficácia de sua prestação jurisdicional perante as múltiplas demandas que se apresentam na atualidade. É fato que a sociedade tem procurado, em progressão acelerada, a resolução de inúmeras situações pela via judicial, o que inicialmente poderia ser entendido como consequência de progresso, no sentido de maior acesso dos indivíduos ao sistema de justiça. No entanto, o que aqui se destaca como aspecto instigante é a busca incessante da "justiça" nas instituições judiciárias, para conflitos e impasses cujas origem e fundamentos fundam-se em variáveis de ordem psíquica, social e relacional e que, por esse motivo, muitas vezes não são solucionados por essa via. Nesse caso, evidencia-se que no contexto de resolução de conflitos temos a configuração de um campo contraditório, no qual se estabelecem relações tensas e paradoxais. Por um lado, é preciso que os conflitos sejam sanados urgentemente; por outro, os mecanismos disponíveis para tal fim se encontram deficitários, seja na esfera individual, das políticas públicas necessárias ou na prestação jurisdicional.

Cabe aqui lembrar que os conflitos são inerentes à condição humana, pois nem todas as necessidades e motivações dos indivíduos podem ser atendidas no momento e da forma desejada. Mas o que encontramos na atualidade é a intensificação da judicialização dos conflitos. Em especial, nos embates entre sujeitos que mantêm ou mantiveram algum tipo de relação afetiva, seja sob a forma de casamento, união estável ou outra modalidade de relação familiar, observa-se facilmente que cada vez mais tem se recorrido ao judiciário para a solução de questões subliminares à demanda jurídica.

Por mais que essas configurações adversárias possuam componentes jurídicos a serem contemplados por ações no sistema de justiça, em parcela significativa de casos não se encontra no judiciário a solução que buscam seus protagonistas. Pois, em função de serem permeadas por aspectos transdisciplinares - para além do campo jurídico —, deflagra-se um embate entre a necessidade de que se encontre uma solução "justa" para situações (o que, na verdade, o sistema de justiça não alcança) e a impotência do judiciário, somada à sua não consideração pela efetiva natureza dessas causas que lá chegam. Isso porque esse poder estatal pode, no máximo, oferecer o controle sobre implementação das leis, e essas passam distante muitas vezes do que poderia ser entendido como justo pelas partes envolvidas.

Outroaspectorelevanteconcerneaotemponecessário para os trâmites jurídicos do ponto de vista institucional, e o tempo de que o indivíduo necessita da perspectiva de sua subjetividade - para que a situação seja resolvida, seja ela emergencial ou não, caracterizada por lentas mudanças psíquicas e relacionais que devem ocorrer para a adaptação do sujeito às possibilidades legais em questão. Em outras palavras: em muitos casos, o "tempo jurídico" é diverso do "tempo subjetivo" de quem busca a justiça.

Apesar desse panorama dissonante entre algumas características do sistema de justiça e da busca do jurisdicionado, na prática se observa que, mesmo não tendo suas expectativas atendidas, quanto ao que seria uma prestação jurisdicional célere, eficiente e eficaz, os indivíduos mantêm demandas repetitivas ao sistema de justiça sob dois aspectos: diferentes pessoas 
adentram ao sistema com necessidades semelhantes e que não foram atendidas eficazmente em outros casos, e também a mesma pessoa recorre a esse sistema inúmeras vezes em relação à mesma causa jurídica.

$\mathrm{Na}$ primeira situação, se inúmeros casos semelhantes são tratados juridicamente de maneira também semelhante e não atingem suas metas, podemos inferir que aqui pode haver manifestações sintomáticas acerca da falta de articulação entre as redes de proteção, defesa e responsabilização de direitos. Da mesma maneira, a "justiça" que se busca talvez não seja a solução jurídica disponível para o caso. Trata-se, muitas vezes, da não consideração de violação de direitos, da inexistência ou ineficácia de políticas públicas relacionadas a essas demandas jurídicas, dentre outros aspectos. No segundo caso, parece que os jurisdicionados percebem de maneira distorcida o que realmente o sistema de justiça pode lhes oferecer, não identificando que em sua demanda jurídica estão implicadas variáveis latentes - mas essenciais - que interferem diretamente tanto na sua aceitação e no cumprimento das decisões judiciais como no reconhecimento de que suas motivações para a busca da "justiça" não poderão ser atendidas no campo jurídico.

No presente estudo será considerada a segunda situação, na qual se evidencia que aspectos de ordem pessoal interferem diretamente nas atitudes do usuário diante do sistema de justiça. Tais aspectos podem ser referentes à situação econômica do indivíduo, à sua condição educacional em termos de nível de escolaridade, às suas urgências práticas referentes a situações específicas de sua vida, e tantas outras particularidades correlacionadas à demanda jurídica. No entanto, aqui será focalizada uma única variável — apesar de um tanto complexa - que é a concepção do indivíduo sobre o conceito de justiça. Sendo assim, o objetivo do presente artigo é analisar o desenvolvimento da formação de conceitos, pois essa parece ser uma via para compreensão de como se dá o processo de conhecer, mais especificamente, como se "conhece" o que é justiça. Para tal finalidade, serão utilizados alguns aportes das ciências cognitivas, procurando integrá-los à construção do conceito de justiça.

\section{Considerações sobre a concepção de justiça}

Entende-se que, ao buscar o judiciário, antes ou concomitantemente, a pessoa tem um conceito prévio de justiça, que fundamenta o teor de sua demanda jurídica - isso é "o que exatamente busca" no judiciário - , assim como influencia também seu entendimento, seu atendimento e sua compreensão dos procedimentos pertinentes à causa jurídica, além de suas atitudes práticas relativas à finalização ou não do processo jurídico e, por fim, sua recorrência às decisões judiciais.

A partir dessas premissas, clarifica-se que nas causas jurídicas não há simplesmente "partes" envolvidas, pois cada procedimento jurídico advém e conduz a inúmeras variáveis, que muitas vezes passam distantes da "simplicidade" da lei positivada. Observa-se, então, um descompasso entre a "lei" procurada e a "lei" possível, denotando que as soluções ofertadas pelo judiciário, em alguns casos, parecem ser antagônicas à demanda do indivíduo. Portanto, faz-se mister investigar que variáveis estão intervindo nessa complexa relação entre o indivíduo e o judiciário e, a partir daí, formula-se a hipótese de que uma delas pode ser o conceito de justiça que cada indivíduo possui. Sendo assim, parece ser uma análise profícua aprofundar-se em como se constrói o conhecimento acerca do conceito de justiça. Esse processo pode ser estudado do ponto de vista acadêmico das produções de conhecimento de juristas, filósofos e outros investigadores do saber jurídico, e também da perspectiva do sujeito envolvido com a justiça.

Se analisada a perspectiva do Direito, inúmeras obras, como as de Maffettone e Veca (2005) e Kymlicka (2006), descrevem o percurso histórico das tentativas de se encontrar parâmetros teóricos, que mesmo apoiados em dados empíricos, demonstram a complexidade da tarefa de se construir um conceito de justiça. Recentemente, a publicação da obra de Sandel (2011) consiste numa contribuição atual, apresentada de maneira criativa e prática sobre o desafio histórico e contemporâneo de se estabelecer o que é justo. Desses autores, detecta-se a diversidade de possibilidades e perspectivas de se definir o que é justiça. Sendo assim, já se pode inferir que o sistema responsável por promover a justiça, apesar de se amparar em instrumental objetivo, tal qual são as leis, enfrenta certamente grandes dificuldades internas na própria instituição judiciária para tomar as decisões "mais justas". Portanto, tem-se abordado, até aqui, um conceito de justiça que estaria "à parte" ou "além" de qualquer sujeito — se é que isso é possível - , tratando-se, portanto, de um conceito teórico.

Psicol. Argum. 2013 jul./set., 31 (73), 529-536 


\section{Ciências cognitivas e o conceito de justiça}

O interesse do presente estudo é de que maneira os indivíduos desenvolvem seu conceito de justiça, o qual pode muitas vezes, ser totalmente desvinculado desse conceito teórico acima abordado. É exatamente nesse ponto que o avanço das ciências da mente, ocorrido intensamente na segunda metade do século $\mathrm{XX}$, têm importante contribuição no entendimento dos processos implicados na construção de conceitos. Mais especificamente, serão utilizadas algumas referências de autores das ciências cognitivas que articulam o conceito de enação ${ }^{1} \mathrm{com}$ o desenvolvimento da cognição.

Inicialmente tem-se algumas reflexões interessantes de Russo e Ponciano (2002) sobre o que as autoras denominam de "re-encantamento" da natureza, como uma alternativa ante a visão dualista mente-corpo. Se antes se entendia de maneira dicotomizada a ideia de que a parte física do ser humano era separada daquelas características que se viam distintivas do homem - pensamento, razão, linguagem, consciência -, o novo momento de resgate da "natureza humana" implica que as qualidades ditas humanas têm assentamento na base natural do homem. Em outras palavras, pode-se qualificar a natureza como possuidora de características anteriormente compreendidas como da "esfera humana" e, sendo assim, para as autoras a natureza em si "é capaz de intencionalidade, autonomia e criatividade" (Russo \& Ponciano, 2002, p. 366). Não se trata mais de entender somente que o ser humano não é dicotomizado em termos mente e corpo, mas que essa separação não faria mais sentido ao mundo dos seres vivos, sendo possível falar, inclusive, em totalidade físico-moral, na qual o mundo físico é dotado de valores que, de alguma forma, determinam os caminhos que a natureza percorre.

No mesmo sentido da visão integrada do conhecimento, Jean Piaget é um dos grandes autores sobre o desenvolvimento da cognição, e o trabalho de Ronald J.J Arendt (2000), "O desenvolvimento cognitivo do ponto de vista da enação", analisa certas críticas direcionadas ao modelo piagetiano e fundamentadas na hipótese de que essa teoria teria alguns aspectos ultrapassados. Mas Arendt (2000) defende a ideia de que, se forem retirados alguns pressupostos kantianos da teoria de Piaget, essa se aproxima das afirmações pragmáticas e enatistas de Richard Rorty e Francisco Varela, respectivamente. Segundo o autor, nesse sentido, o desenvolvimento ocorre pelos processos de assimilação e acomodação que conduzem à reequilibração da rede de crenças e desejos do sujeito, por mecanismos que respeitam etapas sucessivas de organização e reconstrução do material cognitivo. Descreve tal processo denominando-o de acoplagem estrutural, que pressupõe uma relação intrínseca e dual entre o organismo e o meio, incluindo as configurações sociais e políticas desse meio. Para Arendt (2000) essa revisão do modelo piagetiano o aproxima da perspectiva neopragmática contemporânea e da abordagem cognitiva da enação. Como implicação para as pesquisas sobre cognição, tem-se que parece ser mais adequado os estudos do desenvolvimento humano não se assentarem em pressupostos que só relevem as bases biológicas do comportamento, sem considerar os contextos nos quais se dá o desenvolvimento. $\mathrm{O}$ autor alerta ainda, que como consequência, desse entendimento, deve-se também focalizar como se constroem as redes de crenças e desejos, que sofrem constantes acomodações reformulações, dependendo de como ocorre a interação do sujeito com o meio. Em outras palavras, parece que o contexto social tem papel preponderante na construção de conceitos, sem perder de vista que há uma "ação cognitiva" frente à realidade dada e, nas palavras de Arendt (2000), como consequência "o pesquisador daria relevância às capacidades auto-organizadoras das redes construídas, à reflexão do pensamento não tanto como conhecimento obtido, mas como indício de amadurecimento e autonomia do agente percebedor, à ação encarnada". 0 texto é finalizado com a explicitação de uma perspectiva sistêmica de abordagem da questão do desenvolvimento cognitivo, em que o conhecimento depende de experiências sensório-motoras e, portanto, biológicas, mas que se integram dinamicamente a

\footnotetext{
1 "O conceito de enação deriva do inglês to enact, que significa literalmente atuar, por em ato, efetuar. Varela (1998) pretende, com ele, preservar a proximidade entre ação e ator, ou seja, a ação está inevitavelmente ligada a um sujeito, mas este não existe independentemente dela (ser = fazer). Ao mesmo tempo, a enação afirma que o conhecimento não depende unicamente de qualidades intrínsecas do que se conhece, pois este é em-agido, nós fazemo-lo emergir (ser = fazer = conhecer)" (Sade, 2009).
} 
variáveis de ordem psicológica e cultural, conjunto esse que pressupõe uma relação intrínseca entre as partes desse sistema.

Aprofundando os limites e as implicações de uma visão mais restrita à base biológica do conhecimento humano, Mariotti (2000) expõe seus pressupostos:

a) nossa ideia de mundo vem de nossa cognição; b) conhecemos o mundo segundo nossa estrutura; c) essa estrutura cognitiva implica um determinado modo de elaborar o que foi percebido; d) os resultados dessa elaboração orientam nossas ações; e) tais ações têm consequências éticas; f) logo, para mudá-las, é preciso modificar nossas ideias sobre a cognição, o que por sua vez alterará nossa estrutura cognitiva.

Esses fundamentos expostos pelo autor comportam no entendimento do presente estudo uma perspectiva bastante clara e interessante sobre o papel determinante que os processos cognitivos têm sobre nosso comportamento, no sentido de que a cognição é a base e é pela compreensão e abordagem que dela se tem que se vislumbram possiblidades de mudanças de alcance, inclusive social.

Segundo Mariotti (2000), para a abordagem enativa não se dissocia a mente do cérebro, o que ele denomina como mente corporificada. Ainda não se pode esquecer que o cérebro é uma parte de um corpo, sendo este situado no mundo e com um desenvolvimento histórico de sua existência. A relação é, portanto, constante, dinâmica em duplo sentido e ocorre num espaço temporal específico do ciclo vital do indivíduo e do meio. 0 autor afirma que é a essa configuração que Francisco Varela se refere quando defende que a "mente está corporificada no cérebro" (Mariotti, 2000) e, como resultado, não é separada do mundo.

Mariotti (2000) apresenta uma análise importante sobre os desdobramentos, inclusive sociais, acerca da manutenção do entendimento de que há uma verdade única e externa aos indivíduos. Além disso, alerta que o fato de as pessoas pensarem que a realidade existe previamente a sua participação, as coloca numa posição mais passiva e de subserviência ao "mundo real". Essa postura característica do pensamento científico atual, não valida a percepção do indivíduo sobre a realidade. A relação entre o indivíduo e o meio é entendida como linear e, portanto, o modelo mental decorrente dessa premissa também é linear. Segundo o autor, a proposta enativa de entendimento da cognição traz uma nova perspectiva na qual a mente situada leva à possibilidade de mudanças, inclusive nas relações de poder estabelecidas entre os indivíduos.

O artigo de Sade (2009), denominado "Enação e metodologias de primeira pessoa: o reencantamento do concreto das investigações da experiência", consiste em rica contribuição sobre as reflexões das ciências cognitivas decorrentes das metodologias utilizadas para a investigação da experiência. Com o avanço, no fim do século XX, das ciências da mente, uma grande tarefa tem sido abordar a questão da consciência e da experiência; para dar conta dessa empreitada, o autor alerta que as metodologias do pensamento científico tradicional não têm sido adequadas para esse fim que se impôs com o avanço do conhecimento sobre a mente humana. Esse estudo de Sade (2009) se propõe analisar as bases epistemológicas da alternativa a esse problema, que seriam as metodologias de primeira pessoa, a partir da teoria da enação de Francisco Varela.

Um primeiro pressuposto fundamental dessa teoria é que o conhecimento não pode ser separado de quem o conhece. Isto é, o sujeito que conhece e o objeto conhecido são interdependentes, estabelecendo-se aí uma relação de mão dupla na qual o processo cognitivo estudado não se separa da experiência - que implica na corporificação - do sujeito cognoscente. 0 autor tem como intenção, em seu trabalho, demonstrar que essa metodologia é também uma atividade de conhecimento e, sendo assim, não escapa de ter um caráter ontológico.

Para a finalidade deste estudo, que seria encontrar alguns pontos das ciências cognitivas que podem fornecer subsídios para a compreensão acerca do conhecimento do sujeito sobre a temática "justiça", recortaram-se algumas afirmações do artigo de Sade (2009) que parecem ir ao encontro da hipótese deste trabalho: faz-se necessário entender melhor a concepção que os sujeitos têm de justiça e como essa concepção se constrói, para entender a relação muitas vezes ambivalente que o jurisdicionado mantém com o sistema de justiça.

Nesse sentido, cabe ressaltar que enação não conduz ao relativismo, no sentido de haver certa arbitrariedade nas diversas perspectivas do conhecimento. 0 que essa teoria propõe é que o sujeito não se determina por uma perspectiva objetiva do mundo externo, mas que a realidade depende do

Psicol. Argum. 2013 jul./set., 31 (73), 529-536 
indivíduo que a percebe. Para Sade (2009, p. 47), "o mundo relevante é inseparável da sua incorporação". Aqui já se poderia traçar algumas reflexões, no sentido de que, por mais que se postule uma "realidade do sistema de justiça" e do que é objetivamente "legal", essa realidade só passa a existir para o sujeito quando e da forma que ele estabelece uma relação com ela. Talvez se pudesse dizer que o que existe é a "justiça" de cada um. Logicamente, poderia ser pensado que essa afirmação traz mais problemas do que soluções, pois seria impossível gerenciar "bilhões de justiças"! Obviamente, não é essa a intenção. Mas talvez essa perspectiva possa contribuir para que o Direito retome a crença de sua existência "a par" dos homens. Pois, para Sade (2009), o indivíduo não mantém uma relação objetiva com o meio, mas sim esta relação depende de como a realidade é incorporada, o que se traduz num sentido específico do objeto conhecido para quem o conhece. A experiência que o sujeito tem do mundo é, portanto a chave mestra para se entender o processamento da cognição.

Sade (2009, p. 48) amplifica o sentido do que trata de experiência, sendo essa uma "manifestação fenomenal" e com caráter subjetivo. Isto é, ela remete a uma vivência interna única, específica e que se dá quando o indivíduo tem uma relação inteira, direta e inseparável com o mundo cognoscível. Sendo assim a experiência é que leva o indivíduo a existir, ela dá sentido, consciência ao ser. Para o autor, não significa que a cognição se reduz a determinadas estruturas que seriam universais e que qualquer ser as possuísse, mas a proposta enativa entende a cognição como "emergência situada, em ato, singular e concreta" (Sade, 2009, p. 48). Sendo assim, para essa perspectiva, quando se analisa os fenômenos mentais, está implicado um movimento circular das ciências da cognição, pois esses fenômenos serão sempre referentes a um sujeito que os experiencia.

A relação circular entre o indivíduo e o contexto que se estabelece na experiência está implicada no próprio processo de estudo da cognição. Pois, da perspectiva da enação, as teorias da cognição seriam aspectos da relação imbricada entre o cientista cognitivo e o contexto, isto é, refere-se à experiência do cientista e à incorporação que realiza do processo de conhecer.

Trazendo essa perspectiva de que ciência e a experiência humana estão fundamentadas numa relação circular, é possível traçar também algumas articulações com o tema do presente trabalho: a justiça. Sendo assim, a ideia de justiça, quando se configura como um conceito estudado principalmente pelo campo de conhecimento Direito, por tantos autores ao longo da história da humanidade, conforme abordado anteriormente neste texto, parece ter se fundamentado muitas vezes numa concepção do que é justo, que seria afastada da subjetividade humana. Talvez esse fato esteja demonstrando a necessidade de que o campo do Direito, em sua incansável busca por um sistema eficiente e eficaz de promoção de justiça, tenha que tornar mais íntimas suas relações com outros campos do conhecimento que estudam o homem, sob outras perspectivas, como a Filosofia, a Sociologia e a Psicologia. Sanches (2009), em seu artigo "Diálogos entre o Direito e a Psicologia", afirma que ao Direito, na Pós-Modernidade, apresenta-se a tarefa necessária de se fundamentar em novos paradigmas que permitam a esse campo do conhecimento a abertura para a transdiciplinaridade "na solução para a estagnação das fontes jurídicas, de modo a viabilizar a efetivação da verdade real e a maior consideração do ser humano e dos fatores que o envolvem" (Sanches, 2009, p. 29).

Uma das contribuições relevantes, nesse sentido, é o estudo da consciência e, no caso do interesse do presente estudo, a consciência a respeito das implicações subjetivas e práticas da concepção que o indivíduo tem de justiça. Para Sade (2009), a proposta da neurofenomenologia de Francisco Varela implica um método para estudo do que este autor chama de problema difícil da consciência. Os mecanismos funcionais dos processos envolvidos na consciência, que têm sua sede no cérebro e que remetem à discriminação de estímulos, a integração de informações, produção de relatos verbais e controle de comportamento, já são bastante conhecidos pelas ciências cognitivas, e por isso chamados, segundo Sade (2009) de problemas fáceis relativos à consciência. Mas o desafio para os teóricos da cognição está no complexo problema da experiência subjetiva - denominado difícil - , isto é, como os indivíduos percebem a realidade, de que maneira esta se incorpora na mente humana, processo este que implica numa dimensão qualitativa da experiência a qual se articula aos fenômenos cognitivos.

Sade (2009) discorre sobre as críticas à metodologia da introspecção largamente utilizada pela psicologia no final do século XIX, apontando o quanto essa abordagem da experiência tinha uma caráter 
abstrato, no sentido que implicava que o observador refletisse sobre sua experiência como se a estivesse vendo "de fora". A proposta da abordagem enativa seria, ao contrário, pragmática, e, segundo Varela (1996), citado por Sade (2009), com o "desafio de avaliar o conhecimento não pela sua objetividade, mas, sobretudo pelas formas concretas, emergências encarnadas, que ele pode assumir, o que coloca uma questão ético-política" (Sade, 2009, p. 53). Pode-se perceber nessa afirmação a amplitude que a abordagem da enação tem sobre o conhecimento humano, não se restringindo, muito pelo contrário, aos processos fisiológicos da experiência, mas vendo-a como corporificada de um "ser no mundo" com todos os desdobramentos, inclusive nas várias instâncias sociais que esse fato pode ocasionar.

0 mundo não é algo à parte do homem, o mundo é influenciado pelos indivíduos mediante todas as suas ações, por mais elementares que sejam, como o ato de respirar. A relação intrínseca do homem com o mundo aproxima a enação dos pressupostos do paradigma da complexidade. Essa abordagem pode provocar a sensação de relatividade constante, como afirmam Maturana e Varela (1995, p. 259):

Na verdade, todo mecanismo de geração de nós próprios como agentes de descrições e observações nos explica que o nosso mundo, bem como o mundo que produzimos em nosso ser com outros, sempre será precisamente essa mescla de regularidade e mutabilidade, essa combinação de solidez e de areias movediças, tão próprias da experiência humana quando examinada de perto.

Aqui se explicita a perspectiva da complexidade, para a qual, segundo Morin (1996), é pelos indivíduos-sujeitos como seres que emergem da realidade fenomenal e que se dão as infinitas formas de reprodução e, portanto de ação no mundo. Esse caráter de interatividade e circularidade que a abordagem enativa também compartilha é que abre a possibilidade de mudanças, inclusive nos sistemas sociais a partir das "ações e interações" dos seres.

A visão determinista, linear e separatista da ciência não está fadada à exclusão. Mas, como afirma Morin (2005), ela é insuficiente para determinados problemas que se apresentam no século XXI. Sendo assim, parece que o Direito da Pós-Modernidade é convidado a experimentar novos paradigmas em sua doutrina e em sua prática. E, se justiça é um conceito que se constrói a partir da experiência que o indivíduo tem, não só com o aparato legal formal e linear, mas também por inúmeras vivências pelas quais passa, a educação pode ser uma via onde se propiciaria contato como o "mundo da justiça" colaborando para que o sujeito se "aproprie" da justiça. O trabalho de Rouland (2005) discute a iniciação jurídica de adolescentes para que se promova a sensibilização ao direito, uma vez que, normalmente, as normas jurídicas são percebidas como externas aos indivíduos. 0 fato de se oportunizar ao sujeito contatos precoces com a ideia de justiça faz com que este tema se torne presente e corporificado no seu processo de desenvolvimento cognitivo, que passa a ser então partícipe do que chamamos de "realidade justa ou injusta".

\section{Considerações finais}

O sistema de justiça no Brasil tem se confrontado com desafios constantes para atender à crescente demanda nos vários campos do Direito e, sendo assim, o estudo das especificidades dessas solicitações faz-se essencial para que poder judiciário e o sistema de garantias de direitos tenham ações mais profícuas. Embora a abordagem do tema "justiça" remeta a estudos desde a Antiguidade, de importantes nomes da história da Filosofia, ainda existem discussões acerca da origem e formação desse conceito. Sendo assim, com o avanço das ciências da mente, a Psicologia e as Ciências Cognitivas podem contribuir para a elucidação de tarefa tão complexa, demonstrando a essencialidade da construção e experiência do que é "justiça".

0 presente estudo representa, certamente, uma breve introdução à problemática de tal complexidade, deflagrando a necessidade de que o tema seja objeto de pesquisas posteriores. No entanto, a presença das discussões e experiências sobre justiça nos vários âmbitos das relações humanas poderia ser uma estratégia facilitadora para que tal tema fosse mais familiar para cada indivíduo, no sentido de reconhecer a sua concepção de justiça, diferenciando-a do produto ofertado pelo sistema de justiça. Pode ser que, a partir daí, algumas demandas ao judiciário possam sofrer diminuição, principalmente aquelas nas quais há implicações afetivas e relacionais bastante relevantes, que exigem a discriminação pelo sujeito do que realmente busca no

Psicol. Argum. 2013 jul./set., 31 (73), 529-536 
judiciário. Isto é, que ele possa mergulhar na complexidade de sua subjetividade, que certamente não é formada somente por conceitos, e tentar encontrar "sua" resposta para a justiça que demanda.

\section{Referências}

Arendt, R. J. J. (2000). 0 desenvolvimento cognitivo do ponto de vista da enação. Psicologia: Reflexão e Crítica, 13(2). Recuperado em 30 dez., 2012, de http:// www.scielo.br/scielo.php?script=sci_arttext\&pid $=$ S0102-79722000000200003

Kymlicka, W. (2006). Filosofia política contemporânea. São Paulo: Martins Fontes.

Maffettone, S., \& Veca, S. (2005) A ideia de justiça de Platão a Rawls. São Paulo: Martins Fontes.

Mariotti, H.(2000). Ciência cognitiva e experiência humanaCognitivismo, conexionismo e ciência cognitiva: Suas implicações éticas. Recuperado em 10 dez. 2012, de http:// www.geocities.com/pluriversu/cienciac.html

Maturana, H. R., \& Varela, F. (1995). A árvore do conhecimento. Campinas: Editorial Psy II.
Morin, E. (1996). Ciência com consciência. Rio de Janeiro: Bertrand Brasil.

Morin, E. (Org.) (2005). A religação dos saberes. Rio de Janeiro: Bertrand Brasil.

Rouland, N. (2005). Iniciação jurídica dos alunos do segundo grau. In E. Morin (Org.). A religação dos saberes (pp. 481-486). Rio de Janeiro: Bertrand Brasil.

Russo, J. A., \& Ponciano, E.L.T. (2002). O sujeito da neurociência: Da naturalização do homem ao re-encantamento da natureza. PHYSIS: Revista Saúde Coletiva, 12(2), 345-373.

Sade, C. (2009). Enação e metodologias de primeira pessoa: O reencantamento do concreto das investigações da experiência. Informática na Educação: Teoria \& Prática, 12(2), 45-58.

Sanches, A. L. N. (2009). Diálogos entre o Direito e a Psicologia. In M. C. N. Carvalho, T. Fontoura \& V. R. Miranda (Org.). Psicologia jurídica - Temas de aplicação (Vol. 2, pp. 17-30). Curitiba: Juruá.

Sandel, M. J. (2011). Justiça: O que é fazer a coisa certa. (4. ed.). Rio de Janeiro: Civilização Brasileira. 